\title{
In Vitro Antagonistic Activity Evaluation of Lactic Acid Bacteria (LAB) Combined with Cellulase Enzyme Against Campylobacter jejuni Growth in Co-Culture
}

\author{
Dubois-Dauphin, Robin ${ }^{1 *}$, Vandeplas Sabrina ${ }^{2}$, Didderen Isabelle ${ }^{1}$, Marcq Christopher ${ }^{2}$, Théwis André2, \\ and Thonart Philippe ${ }^{1}$
}

${ }^{1}$ University of Liège, Gembloux Agro-Bio Tech, Bio-Industries Unit, Passage des Déportés 2, 5030 Gembloux, Belgium

${ }^{2}$ University of Liège, Gembloux Agro-Bio Tech, Animal Science Unit, Passage des Déportés 2, 5030 Gembloux, Belgium

Received: July 6, 2010 / Revised: October 2, 2010 / Accepted: October 12, 2010

The antibacterial effects of nine lactic acid bacteria (LAB) against Campylobacter jejuni were investigated by using agar gel diffusion and co-culture assays. Some differences were recorded between the inhibition effects measured with these two methods. Only two LAB, Lb. pentosus CWBI B78 and E. faecium THT, exhibited a clear antiCampylobacter activity in co-culture assay with dehydrated poultry excreta mixed with ground straw (DPE/GS) as the only growth substrate source. It was observed that the supplementation of such medium with a cellulase A complex (Beldem S.A.) enhanced the antimicrobial effect of both LAB strains. The co-culture medium acidification and the $C$. jejuni were positively correlated with the cellulase $A$ concentration. The antibacterial effect was characterized by the lactic acid production from the homofermentative $E$. faecium THT and the lactic and acetic acids production from the heterofermentative $L b$. pentosus CWBI B78. The antagonistic properties of LAB strains and enzyme combination could be used in strategies aiming at the reduction of Campylobacter prevalence in the poultry production chain and consequently the risk of human infection.

Keywords: Co-culture, lactic acid bacteria, Campylobacter, cellulolytic enzymes, antagonistic activity, lactic acid, acetic acid

During the last decade, the alimentary toxi-infection due to Campylobacter has considerably increased worldwide [31]. At the same time, "organic" and "traditional" products have

* Corresponding author

Phone: +32 8162 2305; Fax: +32 8161 4222;

E-mail: r.duboisdauphin@ulg.ac.be gained in popularity among consumers [41], and the increased production of such products will not solve food safety problems. The principal source and reservoir of the Campylobacter pathogen is actually poultry and derivate products [40], especially when chickens have access to the outdoors or pasture [9]. A Danish study showed that $100 \%$ of 22 organic broiler-flock samples were positive for Campylobacter spp. compared with $36.7 \%$ of 79 conventional broiler flock samples [14]. A recent epidemiologic study carried out in the southern part of Belgium for one year demonstrated that $100 \%$ of sampled free-range broiler flocks were positive for Campylobacter during the warm season [39]. Campylobacter species are ubiquitous enteric bacteria in the environment and in domestic animal. Thus, they are widely disseminated in the farm environment, and they can be concentrated in raw poultry meat. Because of its susceptibility to multiple environmental stresses (e.g., temperature, relative humidity, and air composition), it is known that Campylobacter does not grow outside its host, but is able to survive in litter [17], in sewage [1], in biofilms formed in the water distribution systems of poultry houses [12], and for more than two weeks in feces [32]. The reduction of Campylobacter contamination at different levels of the poultry production chain, especially at the primary production level, should decrease the risk of human infection. The control of Campylobacter prevalence in broilers is possible but still remains a real challenge. Many different strategies have been developed with more or less success and have been recently reviewed by Lin [16] and Vandeplas et al. [37]. At present, the usual methods that have been implemented to prevent Campylobacter colonization and that have been admitted by sanitary authorities are based on strict biosecurity [Codex Alimentarius Commission, 4]. However, hygiene 
procedures are limited by uncontrollable environmental factors in organics flocks (e.g., open-air range, wild birds, rodents, farm animals, etc.) and by the difficulty to strictly respect biosecurity rules in conventional flocks throughout the rearing stages. In addition, many complementary methods have been developed during the last decade. Acidification of the flock environment (litter, drink water, and feed) was based on the acid susceptibility of Campylobacter [36]. Other investigated strategies include vaccine, phage therapy, or antibiotic uses as growth promoters. However, the latter are completely prohibited by the EU authorities since 2006 [European Economic Community, 8]. However, biological controls, especially microbial competition, are the most investigated approaches $[20,37,44]$. The bacteria most studied belong to the lactic acid bacteria (LAB) group, which have beneficial effects on health and an important role in preserving foods and preventing food poisoning [18]. These bacteria are characterized by their potential to prevent adherence, establishment, replication, and/or virulence of specific enteropathogens [26]. Different antagonistic mechanisms have been proposed; $\mathrm{pH}$ decrease via organic acids production, nutrient competition with pathogens, and/or production of specific inhibitory compounds such as bacteriocins [28]. Thus, the ubiquitous LAB use in the chicken environment (chicken house, litter, pasture, etc.) could reduce the pathogens population and their horizontal transmission in the farm, and could promote animal health.

The primary aim of this research was therefore to establish the effect of some LAB combined with the cellulase A enzymatic complex on growth of the enteropathogen Campylobacter jejuni. The LAB survival in the chicken excreta and their antagonist activity potential could be enhanced by glycanase enzyme, as stated by Vandeplas et al. [38]. These authors showed that a combination between an enzyme of xylanase type and a Lactobacillus strain used as feed additive was able to reduce the Salmonella Typhimurium concentration in caeca of challenged chickens. Enzymes can hydrolyze nondigestible polysaccharides that can be specifically metabolized by LAB. In this study, combinations of LAB strains and a cellulase enzyme were tested in order to further develop anti-Campylobacter treatments to be spread on poultry litter and/or open-air ranges. Thus, the antagonistic activity of different LAB has been tested using the agar gel diffusion and co-culture batch techniques. Subsequently, the cellulase A enzymatic complex was combined with two anti-Campylobacter strains, Lactobacillus pentosus CWBI B78 and Enterococcus faecium THT, in order to assess its ability to improve the antimicrobial activity of both LAB in co-culture. The molecular mechanism involved in antimicrobial activity was investigated by monitoring $\mathrm{pH}$ changes and organic acids levels throughout the time of co-culture.

\section{Materials ANd Methods}

\section{Bacterial Strains}

Nine lactic acid bacteria (LAB), which were isolated from environmental samples of chicken farms, were tested in this study; two Pediococcus pentosaceus (CWBI B73 and CWBI B605), two Enterococcus faecium (THT and CWBI B411), two Paenibacillus spp. (CWBI B1070 and CWBI B60), Weissella confusa CWBI B902, and two Lactobacillus (Lb. pentosus CWBI B78 and $L b$. plantarum CWBI B76) strains. All these strains were obtained from the Walloon Center for Industrial Biology culture collection (CWBI, Gembloux, Belgium), except for E. faecium THT, which was cordially provided by THT s.a. (Gembloux, Belgium); all were characterized phenotypically by using the API 50 CHL System (bioMerieux, Lyon, France) and genetically by $16 \mathrm{~S}$ rDNA sequencing analysis. The LAB cultures were preserved onto Man, Rogosa, and Sharpe (MRS) agar (Biokar Diagnostic, Beauvais, France) and in cryopreservation tubes at $-80^{\circ} \mathrm{C}$. Two $C$. jejuni strains (LMG 6446 and CWBI B1444) and two C. coli strains (LMG 6440 and CWBI B1445) were used as indicator organisms. These strains were kept without antibiotics in Brucella agar and conserved at $-80^{\circ} \mathrm{C}$ in broth medium containing $15 \%(w / v)$ glycerol (Merck, Darmstadt, Germany).

\section{Lactic Acid Bacteria and $C$. jejuni Culture Preparation}

The LAB inoculum was prepared by subculturing bacteria two times in MRS broth $(10 \mathrm{ml})$, at $30^{\circ} \mathrm{C}$. The cells were harvested by centrifuging at $14,000 \times g$ for $5 \mathrm{~min}$, at the end of the log phase. The supernatant was removed and the cells were washed twice in PBS $\left(0.1 \mathrm{M}, \mathrm{pH}\right.$ 7.4). The cells were resuspended to a final $\mathrm{OD}_{560}$ value of approximately 0.1 in Brucella broth, and $0.5 \mathrm{ml}$ of this diluted cell solution was added to an anaerobic flask containing $150 \mathrm{ml}$ of Brucella broth.

Before conducting the agar dilution test or the co-cultures, Campylobacter isolates were streaked from the $-80^{\circ} \mathrm{C}$ stock onto Campy-Cefex agar, without antibiotics, and allowed to grow for $40-48 \mathrm{~h}$ at $42^{\circ} \mathrm{C}$ under a microaerobic environment $\left(5 \% \mathrm{O}_{2}, 10 \%\right.$ $\mathrm{CO}_{2}, 85 \% \mathrm{~N}_{2}$ ). Subsequently, the inoculum was prepared by transferring typical Campylobacter colonies produced on this medium into $10 \mathrm{ml}$ of Brucella broth kept under microaerophilic atmosphere for $48 \mathrm{~h}$.

\section{Assessment of the Inhibitory Activity}

Agar diffusion test. The antimicrobial activity of LAB was screened by the colony-overlay method [29]. The method was modified as follows: $5 \mu \mathrm{l}$ of an overnight culture of LAB was spotted on a fresh MRS plate buffered with sodium phosphate $(0.2 \mathrm{M}, \mathrm{pH} 7)$. The inoculated agar dishes were incubated for $16 \mathrm{~h}$ at $30^{\circ} \mathrm{C}$ and then overlaid with $5 \mathrm{ml}$ of Campy-Cefex soft agar ( $0.5 \%$ agar) supplemented by $8 \mathrm{mM}$ of triphenyltetrazolium chloride (Sigma, St. Louis, MO, USA) and seeded with $0.5 \mathrm{ml}$ of $48 \mathrm{~h}$ microanaerobic Campylobacter culture. A diameter clear zone of $10 \mathrm{~mm}$ or greater, extending laterally from the border of the LAB spot after $24 \mathrm{~h}$ of incubation at $42^{\circ} \mathrm{C}$ under microanaerobic condition, was recorded as positive inhibition.

Co-culture experiments. Dehydrated Poultry Excreta (DPE), from previous feeding trials with broilers housed in raised-floor battery cages with mesh grate floors mounted over excreta collection trays, were prepared by hot drying at $60^{\circ} \mathrm{C}$ for $48 \mathrm{~h}$ and finely ground using a cyclone mill (Cyclotec Sample Mill 1093, Höganäs, Sweden) 
with a 2-mm mesh screen. The sample was added to a co-culture medium as a nitrogen supplement source. Ground Straw (GS), which was ground in a grinder Cyclotec 1093, was used as a carbon source in the co-culture medium.

The co-culture experiments were performed by inoculating the LAB strains with $C$. jejuni LMG 6446 in the same broth culture. The mixed strains were grown in DPE/GS medium containing DPE, $1 \%(\mathrm{w} / \mathrm{v})$; GS, $1 \%(\mathrm{w} / \mathrm{v})$; Tween $80,500 \mu \mathrm{l}$, and peptone, $2 \mathrm{~g} / \mathrm{l}$. All ingredients were mixed thoroughly and autoclaved for $20 \mathrm{~min}$ at $121^{\circ} \mathrm{C}$. A $250-\mathrm{ml}$ anaerobic flask containing $150 \mathrm{ml}$ of sterile medium was inoculated with $1 \mathrm{ml}$ of $C$. jejuni 48 -h culture $\left(\sim 10^{7}-10^{8} \mathrm{CFU} / \mathrm{ml}\right)$ and $0.5 \mathrm{ml}$ of an overnight LAB culture diluted 100-fold $\left(\sim 10^{5}-\right.$ $\left.10^{6} \mathrm{CFU} / \mathrm{ml}\right)$. The microaerobiotic conditions were obtained by flushing the flask with a gas mixture $\left(10 \% \mathrm{CO}_{2}, 5 \% \mathrm{O}_{2}\right.$ and $85 \%$ $\mathrm{N}_{2}$ ) through the medium in the anaerobic culture flask for $20 \mathrm{~min}$. The co-culture flasks were placed on an orbital shaker (Gallenkamp Orbital Incubator; Sanyo, Pocklington, UK) set at $80 \mathrm{rpm}$ for $100 \mathrm{~h}$ at $37^{\circ} \mathrm{C}$. To avoid disturbing the flask microaerobic atmosphere, the samples were withdrawn every $24 \mathrm{~h}$ during the fermentation period.

Numeration of $C$. jejuni and the $\mathrm{LAB}$ strain were performed on co-culture samples. One $\mathrm{ml}$ of sample was serially diluted 10 -fold in bacterial diluent $(8.5 \mathrm{~g} / \mathrm{l} \mathrm{NaCl}, 1.0 \mathrm{~g} / \mathrm{l}$ peptone, and $1 \mathrm{ml}$ Tween 80 , $\mathrm{pH}$ 7.0) and plated on appropriate media described as follows. Campylobacter enumeration was carried out by direct plating onto Campy-Cefex agar with antibiotics $(33 \mathrm{mg} / \mathrm{l}$ cefeperazone and $0.2 \mathrm{~g} / \mathrm{l}$ cycloheximide). Plates were incubated in jars under microaerobic conditions using an Anaerocult $\mathrm{C}$ Gas-Pak envelope (Merck, Darmstadt, Germany) at $42^{\circ} \mathrm{C}$ for $48 \mathrm{~h}$. An enrichment step of $24 \mathrm{~h}$, by incubating $1 \mathrm{ml}$ of first dilution mix into $9 \mathrm{ml}$ of Bolton broth (Oxoid, Basingstoke, UK) at $42^{\circ} \mathrm{C}$ under microaerbic conditions, was carried out in order to confirm the absence of Campylobacter in the samples or to confirm the presence of Campylobacter in samples harboring less than $100 \mathrm{CFU}$ of Campylobacter per milliliter (detection limit of the direct method).

The LAB strains were quantified by plating onto MRS agar supplemented with $0.2 \%$ calcium carbonate, and incubating the plates overnight at $37^{\circ} \mathrm{C}$. Each plating dilution was performed in triplicate for Campylobacter and LAB.

Co-culture: Enzyme effect. To study the enzyme effect on the LAB antagonist activity, the co-culture was supplemented with an enzymatic complex called cellulase A, kindly supplied by Beldem s.a. (Andenne, Belgium). This enzymatic system, extracted from Trichoderma reesei, contains three glycohydrolase activities [endoglucanase (E.C. 3.2.1.4), cellobiohydrolase (E.C. 3.2.1.91), and $\beta$-glucosidase (E.C. 3.2.1.21)] and was chosen for its ability to hydrolyze straw/litter cellulose in easily metabolizable compounds [15]. Cellulase A was diluted in PBS buffer at pH 6 and sterilized by using $0.2 \mu \mathrm{m}$ Pall Acrodisc filter (Pall Life Sciences, St. Germain en Laye, France) before being added into the culture at concentrations ranging from 0 to $500 \mathrm{mg} / \mathrm{ml}$. After $C$. jejuni and LAB co-inoculation in a microaerophilic atmosphere as described above, the co-culture flasks were incubated at $37^{\circ} \mathrm{C}$ for $72 \mathrm{~h}$. Campylobacter and LAB were quantified every $24 \mathrm{~h}$ as described above.

Determination of Co-Culture $\mathrm{pH}$ and Lactate, Acetate, and Glucose Concentrations

Ten $\mathrm{ml}$ of co-culture sample was adjusted to $\mathrm{pH} 10$ with $2 \mathrm{M}$ $\mathrm{NaOH}$, treated with $0.2 \mathrm{~g}$ of polyvinylpolypyrrolidone (Sigma, St. Louis, MO, USA), shook vigorously for $5 \mathrm{~min}$, and subsequently filtered on Whatman No.1 filter (VWR International, West Chester, PA, USA). The filtrate was diluted two times before lactate and acetate concentrations were quantified by high-performance liquid chromatography (HPLC). The HPLC module consisted of a Waters 2690 Alliance System (Waters, Milford, MA, USA ) fitted out with an Aminex HPX-87H column (Bio-Rad, Hercules, CA, USA), a Waters 717 automatic injector (Waters, Milford, MA, USA), a Waters 600 MS pump and system controller (Waters, Milford, MA, USA), and a column oven at $40^{\circ} \mathrm{C}$. The mobile phase was $0.003 \mathrm{~N}$ $\mathrm{H}_{2} \mathrm{SO}_{4}$ at $5 \%(\mathrm{v} / \mathrm{v}) \mathrm{CH}_{3} \mathrm{CN}$ with a flow rate of $0.6 \mathrm{ml} / \mathrm{min}$. The internal standard was isocaproic acid (Sigma, St. Louis, MO, USA), and the compounds were detected by a Waters 486 UV-visible detector (Waters, Milford, MA, USA) at $210 \mathrm{~nm}$. The final glucose content in the co-culture supernatant was measured using an enzymatic glucose assay kit (Megazyme K-GLUC, Wicklow, Ireland). The co-culture $\mathrm{pH}$ was determined directly on samples with a 3151 pH meter (WTW GMBH, Weilheim, Germany).

\section{Chemical Analysis}

Total neutral sugar content in the co-culture medium was quantified with the phenol-sulfuric acid method as described by Dubois et al. [7], whereas, the reducing sugar content was determined using the 3,5-dinitrosalicylic acid (DNS) method [22]. The total Kjeldahl nitrogen and nitrate-nitrogen concentrations in the DPE/GS medium were evaluated by the international standard method (ISO1871:1994) in comparison with Brucella broth supplemented or not with $250 \mathrm{mg} / \mathrm{ml}$ of cellulase A.

\section{Statistical Analyses}

Statistical analysis was conducted with the general linear models procedure (GLM) of SAS (SAS Institute Inc., Cary, NC, USA). The time course of LAB and $C$. jejuni in the co-culture was analyzed by two-way ANOVA, including the effect of the LAB strain $(n=4)$, the sample time $(n=5)$, and any interactions when appropriate. A oneway ANOVA was applied for analyzing the effect of enzyme concentration on LAB antagonist activity (enzyme concentration as fixed factor, $n=5$ ), and metabolic activities of $L A B$ in the co-culture (sample time as fixed factor, $\mathrm{n}=4$ ). Means were compared using the Newman-Keuls test [6] and considered significant at $P<0.05$. Correlations between the glucose and organic acid concentrations in the co-cultures were determined using the CORR procedure of SAS, with a parametric Pearson's test.

\section{ReSUlTS}

Estimation of the antimicrobial activity of LAB against $C$. jejuni/coli, determined with the agar spotting method, is presented in Table 1.

All the tested bacteria were active against $C$. coli, excepted for Paenibacillus strains, which revealed no consistent activity. Five isolates produced antimicrobial substances that were active against at least one of the $C$. jejuni strains used as indicators, and only three isolates $(P$. pentosaceus CWBI B73, E. faecium THT, and $L b$. pentosus CWBI B78) against both $C$. jejuni strains (LMG 6446 and CWBI B1444). No clear inhibition zone was 
Table 1. Antimicrobial activities of lactic acid bacteria selected against Campylobacter indicator strains ${ }^{\mathrm{a}}$.

\begin{tabular}{|c|c|c|c|c|}
\hline \multirow[t]{2}{*}{ Indicator strains } & \multicolumn{2}{|c|}{ C. jejuni } & \multicolumn{2}{|c|}{ C. coli } \\
\hline & LMG 6446 & CWBI B1444 & LMG 6440 & CWBI B1445 \\
\hline E. faecium THT & ++ & ++ & ++ & ++ \\
\hline E. faecium CWBI B411 & - & + & ++ & +++ \\
\hline Lb. plantarum CWBI B76 & - & - & ++ & ++ \\
\hline Lb. pentosus CWBI B78 & ++ & + & +++ & ++++ \\
\hline P. pentosaceus CWBI B73 & + & + & +++ & ++ \\
\hline P. pentosaceus CWBI B605 & - & + & ++ & + \\
\hline W. confusa CWBI B902 & - & - & +++ & ++ \\
\hline Paenibacillus sp. CWBI B1070 & - & - & + & + \\
\hline Paenibacillus sp. CWBI B60 & - & - & + & - \\
\hline
\end{tabular}

${ }^{\mathrm{a}}$ The different scores try to reflect different degrees of growth inhibition; -, no inhibition; +, 10-12 mm inhibition zone; ++, 13-15 mm inhibition zone; +++, 16-18 mm inhibition zone; ++++, 19-20 mm inhibition zone. All indicator strains were assayed at least twice.

observed with Paenibacillus sp. CWBI B1070, Paenibacillus sp. CWBI B60, $W$. confusa CWBI B902, and $L b$. plantarum CWBI B76 with both C. jejuni strains used as indicators.

P. pentosaceus CWBI B73, E. faecium THT, and $L b$. pentosus CWBI B78 were selected for their antimicrobial effects against $C$. coli as well as against $C$. jejuni and were tested in co-culture with $C$. jejuni LMG 6446. Paenibacillus sp. CWBI B1070 was used as a negative reference strain, which does not inhibit the Campylobacter growth. For this experiment, a DPE/GS medium broth co-culture was developed. In comparison with Brucella broth, the analysis of the DPE/GS medium, reported in Table 2, showed a poor availability of $0.364 \mathrm{~g} / \mathrm{l}$ reducing sugars in comparison with $8.847 \mathrm{~g} / \mathrm{l}$ in Brucella broth, whereas the total sugar content was also 2.2 times less important in DPE/GS medium than in Brucella broth. The sugar composition difference between both culture media led to a decrease of the bacterial growth of approximately 1.5 to $2.0 \log _{10} \mathrm{CFU} / \mathrm{ml}$ in DPE/GS medium (data not shown). On the other hand, no significant difference in nitrogen content was reported in total Kjeldahl nitrogen and ammonia nitrogen between DPE/GS medium and Brucella broth. Whereas the DPE/GS medium supplied with cellulase A $(250 \mathrm{mg} / \mathrm{ml})$ increased the reducing sugar and total sugar availabilities, no significant effect was recorded on the percentage of total nitrogen and ammonia nitrogen. Otherwise, it was observed that the C. jejuni LMG 6446 numeration after $48 \mathrm{~h}$ incubation at $37^{\circ} \mathrm{C}$ was not different in DPE/GS medium supplied or not with cellulase A. The Campylobacter cell concentration reached 7.80 and $7.11 \log _{10} \mathrm{CFU} / \mathrm{ml}$ in DPE/ GS medium supplied or not with enzyme and Brucella broth, respectively.

All the LAB strains were in stationary phase after $24 \mathrm{~h}$ in co-culture (Fig. 1A). With initial inocula of approximately $10^{3}-10^{4} \mathrm{CFU} / \mathrm{ml}$, the concentrations of $L b$. pentosus $\mathrm{CWBI}$ B78, P. pentosaceus CWBI B73, and E. faecium THT, were maintained approximately at $10^{8}-10^{9} \mathrm{CFU} / \mathrm{ml}$ from $24 \mathrm{~h}$ of fermentation until the end of experiment, whereas Paenibacillus sp. CWBI B1070 only reached $10^{6}-$ $10^{7} \mathrm{CFU} / \mathrm{ml}$. During the first $24 \mathrm{~h}, \mathrm{pH}$ reduction can be correlated with the log-phase of LAB on each co-culture (Fig. 1B). The highest pH reduction was observed in $E$. faecium THT and Lb. pentosus CWBI B78 co-cultures, reaching 5.8 at $24 \mathrm{~h}$ and 6.0 at $48 \mathrm{~h}$, respectively. Changes in $\mathrm{pH}$ throughout the fermentation did not affect the LAB growth in each co-culture. The $\mathrm{pH}$ reduction during the first $24 \mathrm{~h}$ did not induce any decrease of Campylobacter concentration during this period (Fig. 1C). It was only after $24 \mathrm{~h}$ of fermentation that a slow but steady decline of Campylobacter population was observed in E. faecium THT and Lb. pentosus CWBI B78 co-cultures. No formal correlation could be established between the $\mathrm{pH}$ decrease and the $C$. jejuni inhibition in E. faecium THT and $L b$. pentosus $\mathrm{CWBI} \mathrm{B} 78$ co-cultures. The $\mathrm{pH}$ reduction was observed during the first $24 \mathrm{~h}$ of fermentation, whereas the

Table 2. Effects of sugar and nitrogen sources combined or not with cellulase A on $C$. jejuni growth after $48 \mathrm{~h}$ incubation.

\begin{tabular}{|c|c|c|c|c|c|}
\hline & Reducing sugar & Total sugar & Total Kjeldahl nitrogen & Ammonia nitrogen & C. jejuni growth after $48 \mathrm{~h}$ \\
\hline & Eq. [Glc] g/l & Eq. [Glc] g/l & $\%$ & $\%$ & $\log _{10} \mathrm{CFU} / \mathrm{ml}$ \\
\hline Brucella broth & $8.84 \pm 0.47$ & $9.41 \pm 0.84$ & $7.73 \pm 0.26$ & $0.64 \pm 0.05$ & $7.11 \pm 0.48$ \\
\hline DPE/GS & $0.36 \pm 0.02$ & $4.25 \pm 0.02$ & $7.95 \pm 0.11$ & $0.68 \pm 0.01$ & $7.81 \pm 0.30$ \\
\hline DPE/GS+enz. & $0.67 \pm 0.02$ & $5.15 \pm 0.53$ & $8.00 \pm 0.15$ & $0.71 \pm 0.01$ & $7.82 \pm 0.40$ \\
\hline
\end{tabular}

DPG/GS: Dehydrated poultry excreta $(1 \%, w / v)$ mixed with ground straw $[1 \%(w / v)]$.

enz: cellulase A $(250 \mathrm{mg} / \mathrm{ml})$ 


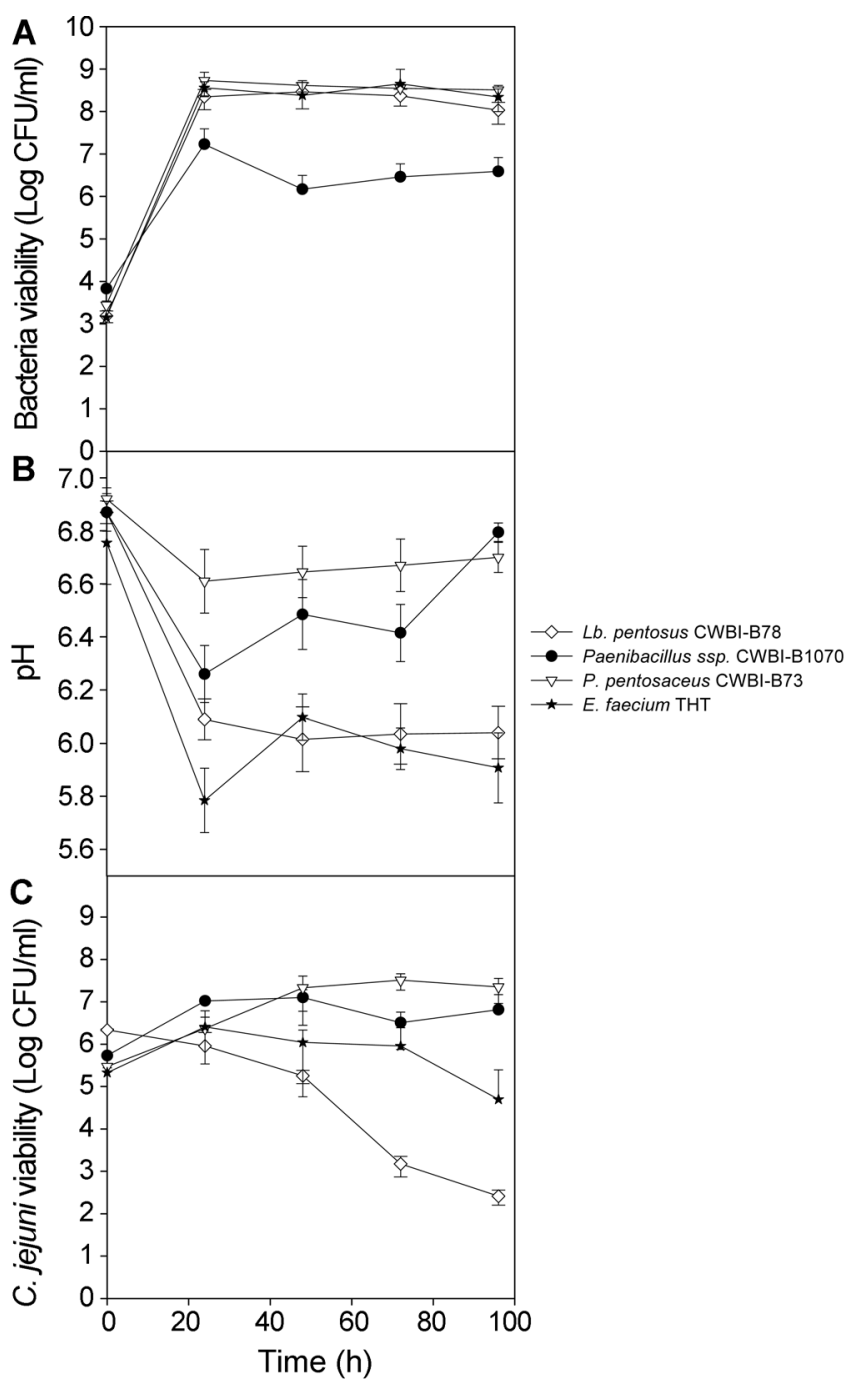

Fig. 1. Time course of lactic acid bacteria and C. jejuni in cocultures.

(A) The viability of LAB; (C) C. jejuni; and (B) $\mathrm{pH}$ evolution in the cocultures. The co-cultures were realized in DPE/GS broth medium under microaerophilic condition at $37^{\circ} \mathrm{C}$, expressed as an average in $\log \mathrm{CFU} / \mathrm{ml}$. Each value shown is the mean \pm SD from at least two experiments.

pathogen concentration only began to decrease from $24 \mathrm{~h}$. After $96 \mathrm{~h}$ of incubation, enteropathogens still survived at $4.6 \log \mathrm{CFU} / \mathrm{ml}$ and $2.4 \log \mathrm{CFU} / \mathrm{ml}$ in the bacterial coculture of E. faecium THT and Lb. pentosus CWBI B78, respectively.

Cellulase A was added to the co-cultures in order to evaluate the possible impact of enzyme treatment on the antimicrobial capacity of LAB. The effect of cellulase A concentration on the inhibition potential was tested on $L b$. pentosus CWBI B78 (Fig. 2A) and E. faecium THT (Fig. 2B) in DPE/GS medium. After $72 \mathrm{~h}$ of fermentation, the enzyme supplementation did not affect LAB growth. However, enzyme enhanced the acidification effect of both strains, which was positively correlated to the enzyme
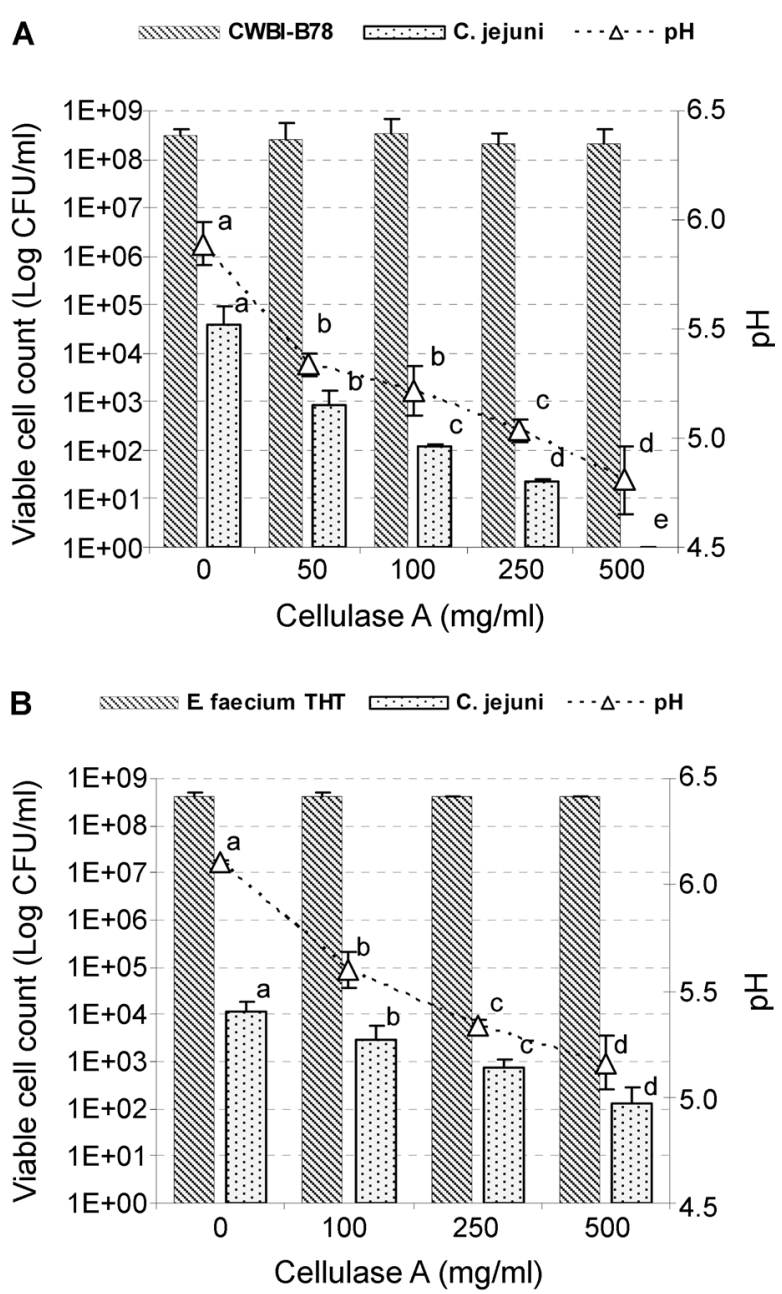

Fig. 2. Effect of enzyme concentration on LAB antagonist activity and $\mathrm{pH}$ in co-culture.

Several concentrations $(0-500 \mathrm{mg} / \mathrm{ml})$ of cellulase A enzyme complex added to co-culture $L b$. pentosus CWBI B78 $+C$. jejuni (A) and E. faecium $\mathrm{THT}+C$. jejuni (B) Bacteria enumeration and $\mathrm{pH}$ in co-culture were determined at $72 \mathrm{~h}$ of incubation under microaerophilic condition at $37^{\circ} \mathrm{C}$. The values are expressed as the mean \pm SD from at least two sets of experiments. ${ }^{\text {ae }}$ Values with different letters at different enzyme concentrations differ significantly $(P<0.0001)$.

concentration. The $\mathrm{pH}$ variation between DPE/GS medium supplemented or not by $500 \mathrm{mg} / \mathrm{ml}$ of enzyme was statistically significant $(\mathrm{P}<0.0001)$ and reached 1.1 and 0.9 $\mathrm{pH}$ units in the Lb. pentosus CWBI B78 and E. faecium THT co-cultures, respectively. The decrease in $\mathrm{pH}$ was correlated $(P<0.0001)$ to the reduction of Campylobacter population in broth fermentations. $C$. jejuni was reduced to an undetectable level after $72 \mathrm{~h}$ in $\mathrm{Lb}$. pentosus CWBI B78 co-culture medium supplemented with $500 \mathrm{mg} / \mathrm{ml}$ of cellulase A (Fig. 2A). Under the same conditions with $E$. faecium THT, the pathogen concentration was stayed at $\sim 10^{2} \mathrm{CFU} / \mathrm{ml}$. It appears, on the one hand, that the enzymatic complex had no bactericidal activity against $\mathrm{LAB}$ as well as against $C$ jejuni (data not shown), but on 

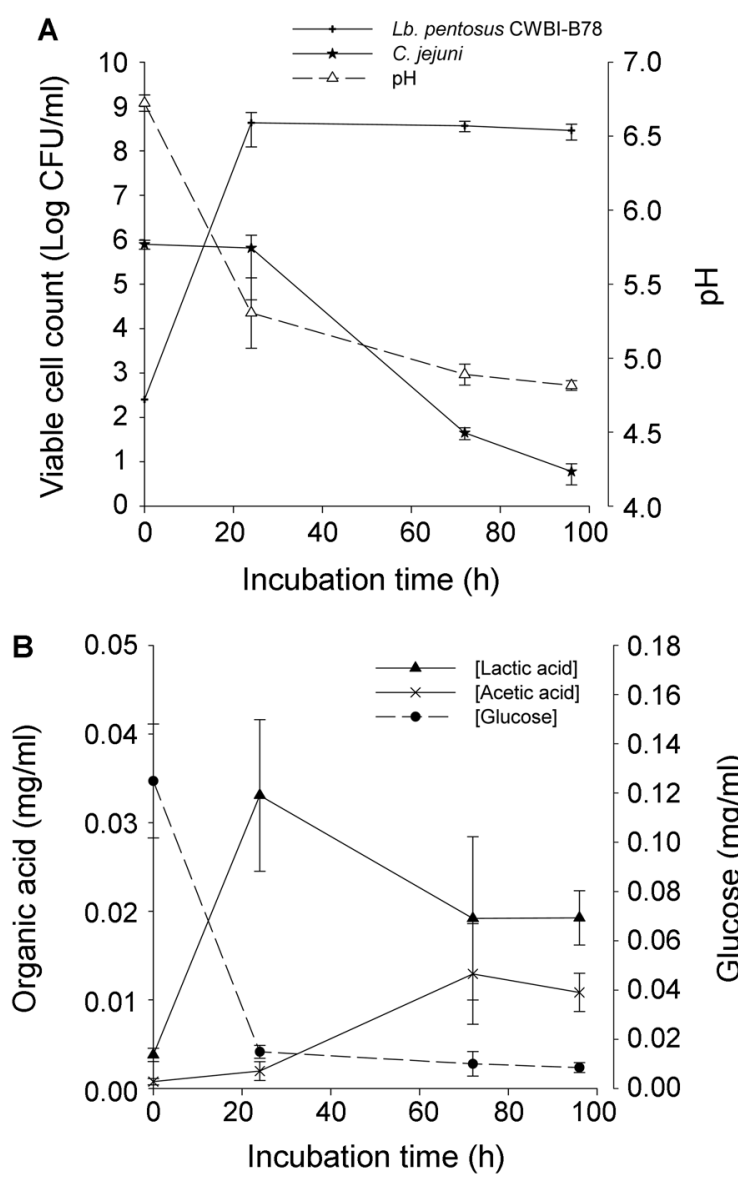

Fig. 3. Metabolic activity of $L b$. pentosus CWBI B78 in coculture.

(A) Growth curves of $L b$. pentosus CWBI B78 and $C$. jejuni and $\mathrm{pH}$ evolution of the medium. (B) Time courses for the concentration of selected metabolites: glucose, lactic acid, and acetic acid. The co-culture was realized in DPE/GS broth supplemented with $250 \mathrm{mg} / \mathrm{ml}$ of cellulase A under microaerophilic condition at $37^{\circ} \mathrm{C}$. Each value is the mean $\pm \mathrm{SD}$ from at least two experiments.

the other hand it improved the LAB antagonism efficiency, probably by releasing oligosaccharides compounds metabolized by LAB but not by Campylobacter, which used amino acids or TCA cycle intermediates.

Organic acids and glucose concentrations were measured throughout the fermentation in $L b$. pentosus CWBI B78 (Fig. 3) and E. faecium THT (Fig. 4) co-cultures supplemented with $250 \mathrm{mg} / \mathrm{ml}$ of cellulase A. The initial inocula were 2.4 and $3.1 \log \mathrm{CFU} / \mathrm{ml}$ for Lb. pentosus CWBI B78 and $E$. faecium THT, respectively (Fig. 3A and 4A). After $24 \mathrm{~h}$, the stationary phase for both LAB strains was reached, with a stable cell concentration of $\sim 8.5 \log \mathrm{CFU} / \mathrm{ml}$ until the end of the experiment. At the same period, the Campylobacter count in both LAB co-culture remained stable at $\sim 5.8 \log \mathrm{CFU} / \mathrm{ml}$. When the antagonistic strains reached the stationary phase $(\sim 24 \mathrm{~h})$ with a mean $\mathrm{pH}$ value of $\sim 5.2, C$. jejuni concentrations decreased in both co-cultures (Fig. 3A and 4A). In the Lb. pentosus CWBI B78 co-culture (Fig. 3A),
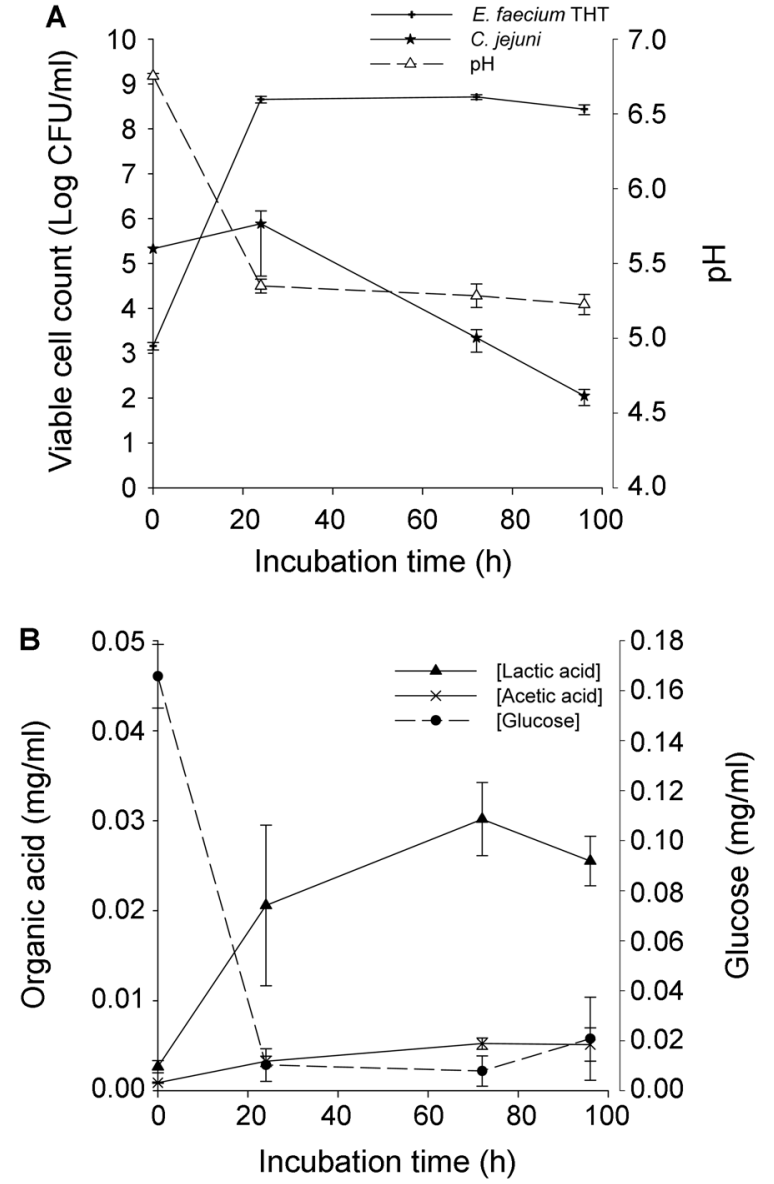

Fig. 4. Metabolic activity of E. faecium THT in co-culture. (A) Growth curves of E. faecium THT and C. jejuni and $\mathrm{pH}$ evolution of the medium. (B) Time courses for the concentration of selected metabolites: glucose, lactic acid, and acetic acid. The co-culture was realized in DPE/GS broth supplemented with $250 \mathrm{mg} / \mathrm{ml}$ of cellulase A under microaerophilic condition at $37^{\circ} \mathrm{C}$. Each value is the mean $\pm \mathrm{SD}$ from at least two experiments.

the $\mathrm{pH}$ declined from about 5.2 after $24 \mathrm{~h}$ to 4.7 at the end of the incubation period, which corresponded to a pronounced decrease of Campylobacter numbers, which was below the limit of detection ( $2 \log \mathrm{CFU})$ at $96 \mathrm{~h}$. In the E. faecium THT co-culture (Fig. 4A), the $\mathrm{pH}$ value was stabilized at $\mathrm{pH} \sim 5.2$ after $24 \mathrm{~h}$; meanwhile, the $C$. jejuni population began to linearly decrease to reach $\sim 2.2 \log$ $\mathrm{CFU} / \mathrm{ml}$ at $96 \mathrm{~h}$.

The glucose concentration in both co-cultures was consumed in less than $24 \mathrm{~h}$ (Fig. 3B and 4B). At the same time, the lactate concentration increased proportionally $(P<0.009)$ to glucose reduction, reaching concentrations of 33 and $21 \mathrm{mg} / 1$ in the Lb. pentosus CWBI B78 and E. faecium THT co-cultures, respectively. After $24 \mathrm{~h}$ of fermentation, the lactate concentration continued to increase up to $96 \mathrm{~h}$, reaching $36 \mathrm{mg} / \mathrm{l}$ in the E. faecium THT co-culture (Fig. 4B). In contrast, the lactate concentration in the $L b$. pentosus CWBI B78 co-culture was decreased at 
the same time, reaching a final value of $19 \mathrm{mg} / \mathrm{l}$ (Fig. 3B). The lactate concentration was negatively correlated to the acetate content in the co-culture medium. The acetic acid concentration increased to reach $12 \mathrm{mg} / \mathrm{l}$ in $\mathrm{Lb}$. pentosus CWBI B78, whereas in E. faecium THT it did not exceed $5 \mathrm{mg} / \mathrm{l}$ (Fig. 4B) after $96 \mathrm{~h}$ of fermentation.

\section{DiscuSsion}

In the first part of this study, results of agar diffusion tests, which were used for estimating the antimicrobial activity of microorganisms from the poultry's environment, confirmed that some LAB have an antagonistic effect against Campylobacter. Most of the studies carried out with LAB strains belonging to the Enterococcus and Lactobacillus genera that were shown to inhibit $C$. jejuni/coli were performed in vitro using the agar gel diffusion test based on the Mayr-Harting method. This method uses culture supernatant from LAB fermentation performed in optimal growth conditions [20]. In this study, the agar gel diffusion method revealed that culture supernatant from $P$. pentosaceus CWBI B73, Lb. pentosus CWBI B78, and E. faecium THT can inhibit $C$. jejuni as well as $C$. coli. These bacterial species are known to produce antimicrobial molecules such as organic acids, fatty acids, ethanol, hydrogen peroxide, and bacteriocins, which have inhibitory effects on Gram positive [10] and negative [25] bacteria. Moreover, the inhibition ability of some LAB has also been demonstrated on Gram-negative bacteria, especially on Campylobacter growth $[5,23,24]$. In our experimental conditions, Paenibacillus sp. CWBI B1070 did not exert any anti-Campylobacter activity, in contrast to the results of Svetoch et al. [33], who reported antagonistic activities against Campylobacter of one Bacillus and three Paenibacillus strains isolated from the poultry production environment.

A co-culture method with a mixed DPE/GS medium was developed in this study and allowed us to directly observe the anti-Campylobacter effect of Lb. pentosus CWBI B78 and E. faecium THT in liquid medium. In comparison with the synthetic Brucella broth, the DPE/GS medium showed significantly different reducing sugars contents, whereas the nitrogen contents were similar. Nevertheless, it appears to be a culture medium as efficient as Brucella broth for co-cultures with Campylobacter. Gilpin et al. [11] have already reported that Campylobacter survive and grow in animal excreta. The co-culture technique allows to further appreciate the impact of LAB strains on the medium culture, on $\mathrm{pH}$ values, and on Campylobacter growth throughout the time course of the experiment. The results of $P$. pentosaceus $\mathrm{CWBI}$ B73 co-culture showed a weak $\mathrm{pH}$ decrease throughout the fermentation, which was related to the absence of Campylobacter reduction, contrary to the results from the agar diffusion method. This strain did not seem to be adapted to the less favorable conditions of the DPE/GS medium. This experiment also confirmed the inability of Paenibacillus sp. CWBI B1070 to be antagonistic against Campylobacter.

The use of exogenous enzymes is a common practice in modern biotechnology industries for biomass valorization, environmental sanitation, and food [42]. Cellulase and hemicellulase enzymes are largely involved in agricultural processes optimization, waste treatment [2], and improvement of feed efficiency and food fermentation [3]. These enzymes hydrolyze the dominant polysaccharides in plant cell wall to oligo/monomers. We hypothesized that these oligo/monomers could be specifically used by LAB strains for growth and metabolic activities. At this stage, $L b$. pentosus CWBI B78 and E. faecium THT were the strains under investigation because of their strong inhibition activity against $C$. jejuni observed with the agar diffusion tests (Table 1). The complementation of the complex enzyme called cellulase A to the DPE/GS medium significantly enhanced the anti-Campylobacter activity of both strains (Fig. 2, 3, and 4). The antagonist capacity of both strains was increased proportionally to the increase of enzyme concentration, confirming the cooperation between celluase A and LAB. These results support the hypothesis that this enzyme could saccharify the cellulosic residues from the DPE/GS medium to more easily fermentable carbon sources. The enzyme use during composting of poultry litter has already been reported by Tiquia et al. [34], who demonstrated that an enzyme consortium (proteases, phosphatases, aminopeptidases, and glycosyl hydrolases) eliminated the fecal coliform population. In the same way, Logan and Bartlett [19] claimed that an enzyme-bacteria combination could act, like competitive exclusion [30], by reducing opportunistic microbes in favor of the bacteria of that present in the complex. Exogenous supplementation of glycohydrolases like cellulase A may support the bacteria, especially during the adaptation or the lag phase. This effect can be explained by enhancing microbial adhesion to a saccharide substrate, which makes substrate capture easier [35].

The antimicrobial activity that was observed in coculture was investigated in the second part of this study in order to elucidate the underlying molecular mechanism of LAB-enzyme antagonism. During the first $24 \mathrm{~h}$ after inoculation of both $L b$. pentosus CWBI B78 and $E$. faecium THT co-cultures, it was observed that the weak Campylobacter population reduction was not correlated with a $\mathrm{pH}$ decrease. The Campylobacter population began to decrease significantly once the culture $\mathrm{pH}$ reached its lowest value, after $24 \mathrm{~h}$ of culture. It appears that a $\mathrm{pH}$ diminution is a prerequisite to trigger the antimicrobial activity of the tested LAB strains. However, the results of lactic and acetic acid concentrations, which were measured by HPLC in co-cultures, suggest that production and high 
concentration in short-chain fatty acids (SCFA) may directly induce Campylobacter inhibition. Indeed, lactate and acetate are major metabolic end products from LAB strain fermentation [28], and their toxicity at low $\mathrm{pH}$ has been explained by transmembrane flux of undissociated SCFA, which ionize in the cell, yielding protons that acidify the alkaline interior of the cell [27]. The timecourse fermentation profile of $L b$. pentosus CWBI B78 clearly showed that this strain produced preferentially lactate during the first hours $(2-24 \mathrm{~h})$ until glucose is consumed. Lactate concentration decreased while acetate was produced after $24 \mathrm{~h}$ of incubation (Fig. 3), probably by shift of the metabolic flux of the hexose monophosphate to the pentose phosphate [43]. The advantage of such of facultative heterofermentative strain is to produce acetate, which has more inhibitory potential against Campylobacter than lactate because of its higher $\mathrm{pKa}$ value [13]. Moreover, the co-culture supplementation with the cellulase A complex enhanced the antimicrobial activity of $L b$. pentosus CWBI B78, which can ferment hexoses as well as pentoses released from the DPE/GS medium. On the other hand, E. faecium is an obligate homofermentative strain, which used hexoses to produce exclusively lactic acid, so its bactericidal effect is more limited (Fig. 2B and 4).

In conclusion, the results of this study demonstrated the antibacterial effect of $L b$. pentosus CWBI B78 as well as E. faecium THT against $C$. jejuni, by the means of coculture techniques and agar diffusion tests. The antagonism was enhanced in co-culture by supplementation of the medium, which was based on dry poultry excreta and ground straw, with the cellulase A complex. This apparent synergistic effect is consistent with observations of other authors with other pathogens. The co-culture model seems consequently to be more relevant than the agar gel diffusion technique to evaluate microbial interactions between an antagonistic strain and $C$. jejuni in a complex ecosystem like poultry litter. It has been pointed out that the inhibitory mechanism underlying this antagonistic effect is the ability of LAB to produce organic acids such as lactic and acetic acids. This work suggests that application of LAB in combination with a cellulase-type in environmental poultry could be used as a method for reducing Campylobacter populations, which could help to lower the risk of contamination in the poultry production industry. This hypothesis needs to be checked by developing an environmental treatment that could be spread on the poultry litter and on the open-air range and by testing in a free-range chicken experiment.

\section{Acknowledgments}

The authors wish to acknowledge Mrs. P. Vanhal for her technical assistance. This work was financially supported by the Directorate for Agriculture, Natural Resources, and Environment (DGARE) of the Walloon Regional Government of Belgium (Research Project D31-1189).

\section{REFERENCES}

1. Abulreesh, H. H., T. A. Paget, and R. Goulder. 2006. Campylobacter in waterfowl and aquatic environments: Incidence and methods of detection. Environ. Sci. Technol. 40: 71227131.

2. Angenent, L. T., K. Karim, M. H. Al-Dahhan, and R. DomiguezEspinosa. 2004. Production of bioenergy and biochemicals from industrial and agricultural wastewater. Trends Biotechnol. 22: 477-485.

3. Bhat, M. K. 2000. Cellulases and related enzymes in biotechnology. Biotechnol. Adv. 18: 355-383.

4. Codex Alimentarius Commission. 2002. Discussion paper on risk management strategies for Campylobacter ssp. in poultry. In $\mathrm{FAO} / \mathrm{WHO}$ (ed.), CX/FH 03/5. Orlando Florida, USA.

5. Chaveerach, P., L. J. Lipman, and F. van Knapen. 2004. Antagonistic activities of several bacteria on in vitro growth of 10 strains of Campylobacter jejuni/coli. Int. J. Food Microbiol. 90: $43-50$.

6. Dagnelie, P. 1996. Théories et Méthodes Statistiques, Vol.2. Presses Agronomiques de Gembloux, Gembloux, Belgium.

7. Dubois, M., K. Gilles, J. K. Hamilton, P. A. Rebers, and F. Smith. 1951. A colorimetric method for the determination of sugars. Nature 168: 167.

8. European Economic Community. 1998. Council regulation (EC) No. 2821/98 of 17 December 1998 on authorisation ban of certain antibiotics concerning the additives in animals food. Vol. L351/4. Off. J. Eur. Communities, Brussels.

9. Esteban, J. I., B. Oporto, G. Aduriz, R. A. Juste, and A. Hurtado. 2008. A survey of food-borne pathogens in free-range poultry farms. Int. J. Food Microbiol. 123: 177-182.

10. Gilliland, S. E. and M. L. Speck. 1977. Antagonistic action of Lactobacillus acidophilus toward intestinal and foodborne pathogens in associative cultures. J. Food Protect. 40: 820-823.

11. Gilpin, B. J., B. Robson, P. Scholes, F. Nourozi, and L. W. Sinton. 2009. Survival of Campylobacter spp. in bovine faeces on pasture. Lett. Appl. Microbiol. 48: 162-166.

12. Trachoo, N., J. F. Frank, and N. J. Stern. 2002. Survival of Campylobacter jejuni in biofilms isolated from chicken houses. J Food Prot. 65: 1110-1116.

13. Heres, L., B. Engel, H. A. Urlings, J. A. Wagenaar, and F. van Knapen. 2004. Effect of acidified feed on susceptibility of broiler chickens to intestinal infection by Campylobacter and Salmonella. Vet. Microbiol. 99: 259-267.

14. Heuer, O. E., K. Pedersen, J. S. Andersen, and M. Madsen. 2001. Prevalence and antimicrobial susceptibility of thermophilic Campylobacter in organic and conventional broiler flocks. Lett. Appl. Microbiol. 33: 269-274.

15. Kumar, R., S. Singh, and O. V. Singh. 2008. Bioconversion of lignocellulosic biomass: Biochemical and molecular perspectives. J. Ind. Microbiol. Biot. 35: 377-391.

16. Lin, J. 2009. Novel approaches for Campylobacter control in poultry. Foodborne Pathog. Dis. 6: 755-765. 
17. Line, J. E. 2006. Influence of relative humidity on transmission of Campylobacter jejuni in broiler chickens. Poultry Sci. 85: $1145-1150$.

18. Ljungh, A. and T. Wadstrom. 2006. Lactic acid bacteria as probiotics. Curr. Issues Intest. Microbiol. 7: 73-89.

19. Logan, T. W. and S. L. Baretlett. 2000. Poultry house litter treatment. United States patent 6,017,525.

20. Mayr-Harting, A., A. J. Hedges, and R. C. W. Berkeley. 1972. Methods for studying bacteriocins, pp. 315-422. In J. R. Norris and D. W. Ribbons (eds.). Methods in Microbiology. Academic Press, London, New York.

21. Mead, G. C. 2002. Factors affecting intestinal colonisation of poultry by Campylobacter and role of microflora in control. World. Poult. Sci. J. 58: 169-178.

22. Miller, G. L. 1959. Use of dinitrosalicylic acid reagent for determination of reducing sugars. Anal. Chem. 31: 426-428.

23. Musikasang, H., A. Tani, A. H-kittikun, and S. Maneerat. 2009. Probiotic potential of lactic acid bacteria isolated from chicken gastrointestinal digestive tract. World J. Microb. Biot. 25: 13371345.

24. Nazef, L., Y. Belguesmia, A. Tani, H. Prevost, and D. Drider. 2008. Identification of lactic acid bacteria from poultry feces: Evidence on anti-Campylobacter and anti-Listeria activities. Poult Sci. 87: 329-334.

25. Ouwehand, A. and S. Vesterlund. 2004. Antimicrobial components from lactic acid bacteria, p. 139-159. In S. Salminen, A. von Wright, and A. Ouwehand (eds.). Lactic Acid Bacteria: Microbiological and Functional Aspects. Marcel Dekker Inc., New York, Basel.

26. Reuter, G. 2001. Probiotics - possibilities and limitations of their application in food, animal feed, and in pharmaceutical preparations for man and animals. Berliner Und Munchener Tierarztliche Wochenschrift 114: 410-419.

27. Russell, J. B. 1992. Another explanation for the toxicity of fermentation acids at low $\mathrm{pH}-$ anion accumulation versus uncoupling. J. Appl. Bacteriol. 73: 363-370.

28. Salminen, S., A. V. Wright, and A. Ouwehand. 2004. Lactic Acid Bacteria: Microbiology and Functional Aspects. Marcel Dekker, New York.

29. Schillinger, U. and F. K. Lucke. 1989. Antibacterial activity of Lactobacillus sake isolated from meat. Appl. Environ. Microbiol. 55: 1901-1906.

30. Schoeni, J. L. and A. C. L. Wong. 1994. Inhibition of Campylobacter-jejuni colonization in chicks by defined competitive-exclusion bacteria. Appl. Environ. Microbiol. 60: 1191-1197.

31. Shane, S. M. 2000. Campylobacter infection of commercial poultry. Rev. Sci. Tech. 19: 376-395.

32. Sinton, L. W., R. R. Braithwaite, C. H. Hall, and M. L. Mackenzie. 2007. Survival of indicator and pathogenic bacteria in bovine feces on pasture. Appl. Environ. Microbiol. 73: 79177925.

33. Svetoch, E. A., N. J. Stern, B. V. Eruslanov, Y. N. Kovalev, L. I. Volodina, V. V. Perelygin, et al. 2005. Isolation of Bacillus circulans and Paenibacillus polymyxa strains inhibitory to Campylobacter jejuni and characterization of associated bacteriocins. J. Food Prot. 68: 11-17.

34. Tiquia, S. M., J. H. C. Wan, and N. F. Y. Tam. 2002. Microbial population dynamics and enzyme activities during composting. Compost Sci. Util. 10: 150-161.

35. Urdaneta, A. B., M. Fondevila, J. Balcells, C. Dapoza, and C. Castrillo. 2000. In vitro microbial digestion of straw cell wall polysaccharides in response to supplementation with different sources of carbohydrates. Aust. J. Agr. Res. 51: 393-399.

36. Van Deun, K., F. Haesebrouck, F. Van Immerseel, R. Ducatelle, and F. Pasmans. 2008. Short-chain fatty acids and L-lactate as feed additives to control Campylobacter jejuni infections in broilers. Avian Pathol. 37: 379-383.

37. Vandeplas, S., C. Marcq, R. Dubois-Dauphin, Y. Beckers, P. Thonart, and A. Thewis. 2008. Contamination of poultry flocks by the human pathogen Campylobacter spp. and strategies to reduce its prevalence at the farm level. Biotech. Agr. Soc. Environ. 12: 317-334.

38. Vandeplas, S., R. Dubois-Dauphin, C. Thiry, Y. Beckers, G. W. Welling, P. Thonart, and A. Thewis. 2009. Efficiency of a Lactobacillus plantarum-xylanase combination on growth performances, microflora populations, and nutrient digestibilities of broilers infected with Salmonella Typhimurium. Poultry Sci. 88: $1643-1654$.

39. Vandeplas, S., R. Dubois-Dauphin, R. Palm, Y. Beckers, P. Thonart, and A. Thewis. 2009. Prevalence and sources of Campylobacter spp. contamination in free-range broiler production in Belgium. Biotech. Agr. Soc. Environ.

40. Wilson, D. J., E. Gabriel, A. J. H. Leatherbarrow, J. Cheesbrough, S. Gee, E. Bolton, et al. 2008. Tracing the source of campylobacteriosis. Plos Genetics 4.

41. Winter, C. K. and S. F. Davis. 2006. Organic foods. J. Food Sci. 71: R117-R124.

42. Wolfgang, A. 2004. Enzymes in Industry: Production and Applications. Wiley-VCH, Weinheim Germany.

43. Zaunmuller, T., M. Eichert, H. Richter, and G. Unden. 2006. Variations in the energy metabolism of biotechnologically relevant heterofermentative lactic acid bacteria during growth on sugars and organic acids. Appl. Microbiol. Biotechnol. 72: 421-429.

44. Zhang, G. D., L. Ma, and M. P. Doyle. 2007. Potential competitive exclusion bacteria from poultry inhibitory to Campylobacter jejuni and Salmonella. J. Food Prot. 70: 867873. 